\title{
On deterrence
}

\author{
WILLIAM PAUL LIVANT
}

\section{Mental Health Research Institute, The University of Michigan}

Every notion of deterrence with which I am familiar depends upon the idea of a credible threat; namely, that a threat will be (a) understood, (b) feared, and (c) provoke a rational response to fear in the threatened party. But the effect of threatinduced fear on rationality cannot be taken for granted. If it should be the case that its effect is to impair rationality, deterrent threats are open to serious question.

What, in fact, does fear do to rationality? Fear has been studied extensively in the psychological literature as a drive. Easterbrook, (1) reviewing a large literature on individual performance under drive, makes an impressive case for the proposition that the effect of increased drive on problemsolving is to reduce the range of clues employed by the organism. If the clues necessary for solution are indeed few, then increased drive, by eliminating distracting ones, may actually improve performance. But as a problem becomes more complex, the necessary clues increase along with the number of rules for combining them. Performance under high drive in such a situation is likely to be seriously impaired.

It appears that threats are becoming more complex, for reasons that lie in the character of modern war. If a threat fails and has to be carried out, it is costly to both parties, and modern weapons have made this cost so high indeed that some strategists have been looking for ways to retain the credibility of threat without incurring the costs (i.e., without absolutely having to deliver it). Schelling (2) suggests "the threat that leaves something to chance," so that the threatened party does not know whether a threat will be fulfilled for any particular infraction, since the threatener has surrendered part of his control of the threat to some chance device (e.g., "If you make me mad, there's no telling what I might do"). The extreme threat of this sort is brinkmanship, where all of the elements of threat, its character, its probability, and the kind of infractions for which it will be invoked are left partly to chance.

I believe that the more a threat leaves something to chance, the more complex becomes the problem of understanding it. Since there are more problematical features in the threat, we present the other party with a problem of more clues to consider. But to the degree that our threat is successful in arousing fear, it will narrow the range of clues which the threatened party does consider. I think it is not unfair to say that it impairs his rationality. The deterrent outcome of a threat may well become more dubious, the more it succeeds in compelling fear.

\section{REFERENCES}

1. Easterbrook, J. A. "The Effect of Emotion on Cue Utilization and the Organization of Behavior," Psychological Review 66, 3 (1959), 183-201.

2. Schelling, Thomas C. The Strategy of Conflict. Cambridge, Mass.: Harvard University Press, 1960, ch. 3. 